\title{
УПРАВЛЕНИЕ
}

\section{ПОЛИЦЕЙСКОЙ ДЕЯТЕЛЬНОСТЬЮ}

Паньшин Д.Л., Дресвянникова Е.А.

\section{ПРОБЛЕМЫ УПРАВЛЕНИЯ КОНФЛИКТАМИ В ПОДРАЗДЕЛЕНИЯХ ГОСАВТОИНСПЕКЦИИ РОССИИ}

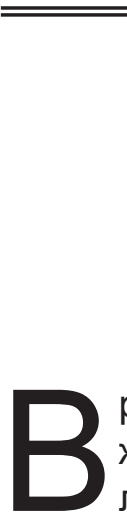

различных сорерах современной жизни общества наблюдается усиление конфликтности и тревожности, что в большей степени объясняется глобализацией информационного потока. Век высоких технологий «съедает» нервную психическую систему человеческого организма. Физическое и эмоциональное истощение присущи практически каждому профрессионально занятому человеку.

Работа сотрудников Государственной инспекции безопасности дорожного движения Министерства внутренних дел Российской Федерации (далее - ГИБДД) связана с большими нервно-психическими нагрузками. Действительно, условия работы сотрудников ГИБДД далеко не комфортные. Здесь имеются в виду не только фризиологические фракторы, связанные с условиями труда: гиподинамия, повышенная нагрузка на зрительный, слуховой и голосовой аппараты и т. д. Речь идет, прежде всего, о психологических и организационных трудностях: необходимость быть все время «в форме», отсутствие эмоциональной разрядки, большое количество контактов в течение рабочего дня и т. д. В совокупности всех
«Конфрликт сам по себе злом не является, скорее речь идет о френомене, который может иметь конструктивные или деструктивные последствия в зависимости от того, как им управляют»

Льюис Козер

этих фракторов возникает синдром профессионального выгорания.

Также стоит отметить, что на общие условия деятельности подразделения организация и условия труда, порядок поощрений и премирования, распределение отпусков, перспективы служебного роста, обеспеченность жильем и т. п., существенное влияние оказывает характер отношений в коллективе. На наш взгляд, большую ответственность за тот социально-психологический климат, который сложился в коллективе, и в котором пребывают сотрудники органов внутренних дел МВД России (далее - ОВД), несет руководитель.

Анализ профессиональной деятельности руководителей ОВД показывает, что деятельность последних также протекает в условиях высокой психической напряженности, которая как следствие ведет к увеличению риска развития некоторых заболеваний стрессовой этиологии - «болезней стресса» (сердечно-сосудистые, язвенные болезни, невротические состояния и др.) $)^{1}$. Кроме того, деятельность ру-

${ }^{1}$ Гринберг Дж.С. Управление стрессом. - СПб.: Питер, 2004. 
ководителя в состоянии стресса приводит к нарушению социально-психологического климата в коллективе, и более того влечет целый ряд социально-психологических последствий: текучесть кадров, неполное и несвоевременное выполнение служебных задач, снижение удовлетворенности трудом, деформацию личностных и характерологических качеств руководителя.

В феврале-марте 2013 года нами были обследованы 40 руководителей подразделений ГИБДД МВД России (начальники (заместители) отделов (отделений) ГИБДД территориальных органов МВД России на районном уровне) из 24 регионов России. При обследовании использовались тесты, включающие в себя психодиагностические методики исследования конфликтности и тревожности ${ }^{2}$. Общее число руководителей с высокой тревожностью составило 10 \% от общего числа обследованных; со средним уровнем тревожности $82 \%$; низкий уровень тревожности выявлен у 8 \% руководителей от общего числа обследованных. В результате сделан вывод, что большинство обследуемых руководителей подразделений ГИБДД, на сегодняшний день, повышают требования к своим личностным и профессиональным качествам, способны правильно оценивать мотивы своей деятельности и осознавать себя активными личностями, что особенно актуально в условиях реформирования системы МВД России.

Диагностика конфликтности помогла нам выявить предпочтительные линии поведения руководителей подразделений ГИБДД в служебных конфликтах. Было установлено, что наиболее предпочтительной линией (стратегией) поведения руководителей является компромисс 28 \% от общего числа обследованных. Руководители согласились с данным общим

\footnotetext{
2 Стратегии поведения руководителей подразделений ГИБДД в служебных конфликтах определялись по методике Томаса-Килмена; уровень тревожности - по методике Спилберга.
}

показателем, отметив, что при возникновении конфрликтных ситуаций им чаще приходится выстраивать баланс интересов конфликтующих сторон. Мы также должны учитывать, что такая позиция руководителей объяснима ростом их профессионального и социального опыта. Вместе с тем, отметим, что компромисс нельзя рассматривать как способ разрешения конфликта, он часто является лишь этапом на пути поиска приемлемого решения проблемы, хотя иногда компромисс может исчерпать конфликтную ситуацию.

На втором по предпочтению находится стратегия избегания - 34 \% от общего числа обследованных, которая характеризуется стремлением уйти от конфликта. Руководителями данная линия поведения была обоснована тем, что стратегией ухода, конфликт исчерпывается. Сложившиеся в прошлом стереотипы ориентировали руководителей на бесконфликтное развитие коллективов, именно поэтому они стремятся избегать противоречий даже в ущерб интересам дела, так как столкновение взглядов в коллективе часто воспринимается как недостаток работы самого руководителя.

Однако 43 \% от общего числа обследуемых, подтвердило, что это не самая лучшая линия поведения, так как стратегией ухода конфликт не исчерпывается, а остается и порой может возобновиться с еще большей силой. Кроме того, позиция ухода говорит о низкой профессиональной компетентности руководителя.

На третьем месте оказалась стратегия сотрудничества - 33 \% от общего числа обследованных. Руководители признавали необходимость учета в возникающих конфликтных ситуациях, как личных интересов, так и интересов соперника, обосновывая данный выбор поведения необходимостью поддержания благоприятного климата в коллективе, который, по их мнению, строится на балансе интересов, на признании взаимоуважительных отношений 


\section{Полицейская деятельность 2 • 2014}

между сотрудниками внутри коллектива, между руководителем и подчиненными.

Четвертым в рангах стратегий оказалось приспособление - 24 \% от общего числа обследованных. Приспособление, как и избегание, характеризуется стремлением уйти от конфликта. Но причины ухода от конфликта в случаях приспособления связаны с тем, что человек, принимающий данную стратегию, жертвует личными интересами в пользу интересов соперника. В ходе обсуждения 35 \% от общего числа обследуемых руководителей посчитали стратегию приспособления тактическим шагом на пути достижения какой-либо цели, грамотным управленческим решением в определенных конфликтных ситуациях.

Выбор в пользу соревнования (соперничества) был отмечен лишь у $25 \%$ обследуемых руководителей. При обсуждении данной стратегии руководителями подразделений ГИБДД была высказана точка зрения, свидетельствующая о необходимости исключения данной линии поведения при управлении конфлликами в подразделениях ОВД. Замечено, что при такой стратегии используется власть, связи, авторитет и пр. Однако при всей деструктивной составляющей она является целесообразной и эффрективной в случаях, когда интересы службы могут быть нарушены и когда требуется повысить работоспособность коллектива, или вообще сохранить не просто коллектив профессионалов, а профессиональный коллектив. В таких ситуациях именно конфликт помогает выявить разнообразие точек зрения, альтернатив, дает дополнительную информацию, делает процесс принятия решения более эффрективным.

Анализируя полученные данные нами была выявлена фракторная структура психологических показателей возникновения конфрликтных ситуаций по вине руководителей:

1. Личностная незрелость (непринятие ответственности на себя; игнорирование проблем подчиненных).
2. Как результат личной незрелости, на наш взгляд, является агрессивное поведение в деятельности (несдержанность; непринятие ответственности за конечный результат).

3. Подозрительность и осторожность при решении служебных задач.

4. Формализм в деятельности (отсутствие стремления к новому).

5. Отсутствие гибкости при решении служебных задач (отсутствие профессиональной смелости).

6. Неспособность к самостоятельному решению служебных задач (отсутствие стремления к самостоятельному решению проблем).

Вследствие этого, в последнее время, возрастает интерес психологов к разрешению противоречия между теоретическим и практическим изучением конфоликтов в подразделениях правоохранительных органов. Запросы практики по управлению конфликтами не соответствуют теоретическим возможностям современной психологии, требуют детальных рекомендаций по работе с конфликтами.

На наш взгляд, для эфффективного решения возникающих проблем каждому сотруднику ОВД необходимо усвоить определенный минимум теоретических знаний и практических навыков поведения в конфрликте, то есть получить конфрликтологическую подготовку.

К сожалению, большинство сотрудников МВД не имеют достаточной психологопедагогической подготовки для того, чтобы проанализировать внутренние и внешние причины конфллика, разобраться в параметрах, структуре, закономерностях их возникновения, протекания и разрешения.

Опрос сотрудников МВД РФ показал, что многие из них не могут назвать ни одного способа предупреждения и разрешения конфликтов.

Конфликтологическая подготовка поможет сотруднику ОВД лучше ориентироваться в сложной социальной действи- 
тельности, находить верные решения в нестандартных ситуациях, эффрективно обеспечивать охрану общественного порядка и борьбу с преступностью в экстремальных условиях ${ }^{3}$.

Большая роль в этом вопросе отводится руководителю. Очевиден тот фракт, что успех деятельности подразделений ГИБДД зависит от умения руководителей планировать свое рабочее время, их способности устанавливать приоритетность задач, правильно распределять нагрузку. Кроме того, высокую значимость имеет владение и использование руководителями в своей профессиональной деятельности методов диагностики, разрешения и психопрофилактики конфликтных ситуаций. Эта способность является одной из составляющих профессионализма каждого руководителя.

Однако, как показали проведенные нами опросы, многие руководители ОВД и подразделений ГИБДД в частности, либо стремятся, в большинстве случаев, подавлять конфрликты, либо не хотят вмешиваться в них. Обе позиции обосновывались руководителями их недостаточной подготовленностью в психологическом плане для компетентного и квалифицированного участия в данном процессе.

В системе ОВД большинство конфликтных межличностных и межгрупповых взаимоотношений разрешаются не путем психологии, а путем жесткого вертикального управляющего воздействия.

Полагаем, что руководителям ОВД при управлении конфликтами стоит руководствоваться следующими рекомендациями.

В конфрликтной ситуации руководителю нельзя:

- критически оценивать участника (участников) конфликта;

- приписывать низменные или плохие намерения оппоненту;

\footnotetext{
${ }^{3}$ Самсонова Н. В. Конфликтологическая культура специалиста и технология ее формирования в системе вузовского образования: Монография. - Калининград: Изд-во КГУ, 2002. (ISBN 5-88874-393-3).
}

- демонстрировать знаки превосходства;

- обвинять и приписывать ответственность только оппоненту;

- игнорировать интересы противоборствующей стороны;

- видеть все только со своей позиции;

- уменьшать заслуги оппонента (подчиненного сотрудника) и его вклад;

- преувеличивать свои заслуги;

- раздражаться, кричать, нападать (терять самообладание);

- задевать «болевые точки» и уязвимые места оппонента;

- обрушивать на оппонента множество претензий.

Кроме того, если руководитель оказал-

ся «втянутым» в спор, или принимает активное участие в споре, ему необходимо:

- не быть предвзятым, даже при разных взглядах выявить хоть одну общую точку зрения;

- не давать втянуть себя в пустую словесную перепалку;

- не терять самообладания: бестактность, брань - признак слабости и отсутствия аргументов;

- опираться на фракты и логику;

- быть лаконичным;

- прогнозировать последствия своих слов;

- не бояться критики в свой адрес, так как она помогает увидеть слабые места;

- уметь признать свою ошибку;

- избегать нечестных приемов в споре.

Стоит отметить, что выбор руководителем своей роли в разрешении конфликта строится на том, что, обладая властью над подчиненными, он может выступить в образе судьи, арбитра, помощника, посредника или же простого наблюдателя. Представляется, что каждый руководитель, выбрав ту или иную роль должен провести раздельные беседы с каждым участником конфликтной ситуации, подготовить и себя и оппонентов к совместному решению проблемы. С согласия всех сторон конфликта 


\section{Полицейская деятельность 2 • 2014}

проблема может быть вынесена на обсуждение коллектива. Кроме того, для снятия послеконфрликтного напряжения именно руководителю необходимо помочь сотрудникам осуществить самокритичный анализ конфликта, чтобы не допустить негативных установок в отношениях, что также будет способствовать оптимизации социальнопсихологического климата в коллективе. В этом состоит немаловажная роль руководителя, как управляющего звена.

Однако реалии сегодняшних дней таковы, что не каждый сотрудник и руководитель, сталкиваясь с конкретной конфрликтной ситуацией и сетуя на специфику работы, плохие личностные качества других сотрудников, способен понять и увидеть насколько он сам, его недостатки являются причиной конфлликтных ситуаций. Именно поэтому, нам представляется необходимым обозначить основные направления деятельности руководителей ОВД по управлению конфликтами и их профилактике.

Во-первых, каждый начальник подразделения, от начальника отделения до руководителя управления обязан проводить индивидуальную воспитательную работу с подчиненными, изучать и понимать особенности характера того или иного сотрудника. При этом следует учитывать не только индивидуальные черты характера отдельных сотрудников, но и то общее, что свойственно той или иной группе сотрудников.

Во-вторых, создание общей оптимальной атмосферы в коллективе зависит от добросовестного исполнения возложенных на сотрудников обязанностей, что есть следствие грамотного распределения руководителем фрункциональных обязанностей между подчиненными.

В-третьих, каждому руководителю необходимо научиться анализировать каждую конфликтную ситуацию, возникающую в его коллективе, так как анализ полученного опыта позволит руководите- лю осмыслить не только действия и поступки противоборствующих сторон, но и свои действия, оптимизировать алгоритм действий по регулированию конфрликтов среди подчиненных.

Кроме того, стоит особо подчеркнуть, что профессиональная деятельность каждого руководителя ОВД и подразделений ГИБДД, в частности, неразрывно связана с социально-психологическими процессами, протекающими в коллективе, поэтому каждому руководителю необходимо вырабатывать свой индивидуальный стиль управления. Как отмечает В. Г. Атаманчук «через стиль своего воздействия руководитель оказывает влияние на складывающиеся в коллективе отношения, процессы и взаимосвязи, реализует свои целеполагающие, организующие и регулирующие функции».

На наш взгляд, в условиях реформирования системы МВД России, все больше внимания уделяется новым требованиям к стилю работы руководителей ОВД. Общими среди них можно выделить следующие: творческий подход, научность, деловитость, чуткое отношение к людям, использование информационных технологий, непримиримость к недостаткам, применение тактических приемов управления конфрликтами в служебном коллективе.

Таким образом, целенаправленное использование законных тактических приемов, изменяющих социально-психологический климат коллектива в благоприятную сторону - это один из способов формирования мотивации бесконфрликтного поведения у подчиненных.

Квалифицированное разрешение конфрликтов руководителями ОВД - это ответственное и при этом эффрективное направление их деятельности, способное инновационным образом повлиять на преобразование правоохранительной системы. Следовательно, в условиях реформирования системы МВД России общая задача руководителя ОВД заключается в правильном 


\section{Управление полицейской деятельностью}

регулировании взаимоотношений между сотрудниками, в воспитании у каждого из них сознательного отношения к людям и к своим обязанностям, в создании таких ус- ловий деятельности, при которых каждый член коллектива имеет возможность наращивать свой личностно-профессиональный потенциал.

\section{Библиография:}

1. Дорохова А. П., Ратова И. В. Оптимизация социально-психологического климата в служебном коллективе: Инструментальный тренинг. - Домодедово: ВИПК МВД России, 2007.

2. Атаманчук Г. В. Теория государственного управления: учебник для высшей школы: курс лекций. М., 2005.

3. Алейников А.В. Системные конфликты в России: концептуальные основания анализа. Статья II. // NB: Проблемы общества и политики. - 2013. - 8. - C. 1-47. DOI: 10.7256/23060158.2013.8.5109. URL: http://www.e-notabene.ru/pr/article_5109.html

4. Алейников А.В. Системные конфликты в России: концептуальные основания анализа. Статья 1. // NB: Проблемы общества и политики. - 2013. - 7. - C. 94-140. DOI: 10.7256/23060158.2013.7.2306. URL: http://www.e-notabene.ru/pr/article_2306.html

5. Перов Е.В. Теория и анализ социальной конфликтогенности общества // NB: Национальная безопасность. - 2013. - 5. - C. 67-141. DOI: 10.7256/2306-0417.2013.5.2308. URL: http:// www.e-notabene.ru/nb/article 2308.html

6. Манойло А.В. Ценностные основы управления межцивилизационными конфликтами: российская модель // NB: Международные отношения. - 2012. - 1. - C. 32-43. URL: http:// www.e-notabene.ru/wi/article_279.html

7. Мартынов А.В. Современное право и публичное управление: проблемы методологии и соотношения // NB: Экономика, тренды и управление. -2013. -4. - C. 1-15. DOI: 10.7256/23064595.2013.4.924. URL: http://www.e-notabene.ru/etc/article 924.html

8. Гуляихин В.Н. Правовой менталитет российских граждан // NB: Вопросы права и политики. - 2012. - 4. - C. 108-133. URL: http://www.e-notabene.ru/lr/article_310.html

9. Трунцевский Ю.В., Новоселов С.А. Повышение эффективности предупреждения преступлений и иных правонарушений, коррупционной направленности, совершаемых сотрудниками ГИБДД, как условие организации дальнейшего реформирования ОВД РФ согласно Дорожной карте // NB: Административное право и практика администрирования. - 2013. - 5. - С. 45-61. DOI: 10.7256/2306-9945.2013.5.8843. URL: http://www.e-notabene.ru/al/article 8843.html

10. Овсянникова О.А., Кузнецова А.А. исторические и современные социально-политические основы российского патриотизма // NB: Международные отношения. - 2013. - 3. - С. 87-114. DOI: 10.7256/2306-4226.2013.3.9083. URL: http://www.e-notabene.ru/wi/article_9083.html

11. О. Г. Канторович Россия: проблемы выработки национальной стратегии политического управления современными международными конфликтами // Политика и Общество. 2011. - 8. - C. 48 - 59.

\section{References (transliteration):}

1. Dorokhova A. P., Ratova I. V. Optimizatsiya sotsial'no-psikhologicheskogo klimata v sluzhebnom kollektive: Instrumental'nyi trening. - Domodedovo: VIPK MVD Rossii, 2007. 


\section{Полицейская деятельность $2 \cdot 2014$}

2. Atamanchuk G. V. Teoriya gosudarstvennogo upravleniya: uchebnik dlya vysshei shkoly: kurs lektsii. M., 2005.

3. Aleinikov A.V. Sistemnye konflikty v Rossii: kontseptual'nye osnovaniya analiza. Stat'ya II. // NB: Problemy obshchestva i politiki. - 2013. - 8. - C. 1-47. DOI: 10.7256/2306-0158.2013.8.5109. URL: http://www.e-notabene.ru/pr/article_5109.html

4. Aleinikov A.V. Sistemnye konflikty v Rossii: kontseptual'nye osnovaniya analiza. Stat'ya 1. // NB: Problemy obshchestva i politiki. - 2013. - 7. - C. 94-140. DOI: 10.7256/2306-0158.2013.7.2306. URL: http://www.e-notabene.ru/pr/article_2306.html

5. Perov E.V. Teoriya i analiz sotsial'noi konfliktogennosti obshchestva // NB: Natsional'naya bezopasnost'. - 2013. - 5. - C. 67-141. DOI: 10.7256/2306-0417.2013.5.2308. URL: http://www.enotabene.ru/nb/article_2308.html

6. Manoilo A.V. Tsennostnye osnovy upravleniya mezhtsivilizatsionnymi konfliktami: rossiiskaya model' // NB: Mezhdunarodnye otnosheniya. - 2012. - 1. - C. 32-43. URL: http://www.e-notabene.ru/wi/article_279.html

7. Martynov A.V. Sovremennoe pravo i publichnoe upravlenie: problemy metodologii i sootnosheniya // NB: Ekonomika, trendy i upravlenie. - 2013. - 4. - C. 1-15. DOI: 10.7256/23064595.2013.4.924. URL: http://www.e-notabene.ru/etc/article_924.html

8. Gulyaikhin V.N. Pravovoi mentalitet rossiiskikh grazhdan // NB: Voprosy prava i politiki. - 2012. - 4. - C. 108-133. URL: http://www.e-notabene.ru//r/article_310.html

9. Truntsevskii Yu.V., Novoselov S.A. Povyshenie effektivnosti preduprezhdeniya prestuplenii i inykh pravonarushenii, korruptsionnoi napravlennosti, sovershaemykh sotrudnikami GIBDD, kak uslovie organizatsii dal'neishego reformirovaniya OVD RF soglasno Dorozhnoi karte // NB: Administrativnoe pravo i praktika administrirovaniya. - 2013. - 5. - C. 45-61. DOI: 10.7256/23069945.2013.5.8843. URL: http://www.e-notabene.ru/al/article_8843.html

10. Ovsyannikova O.A., Kuznetsova A.A. istoricheskie i sovremennye sotsial'no-politicheskie osnovy rossiiskogo patriotizma // NB: Mezhdunarodnye otnosheniya. - 2013. - 3. - C. 87-114. DOI: 10.7256/2306-4226.2013.3.9083. URL: http://www.e-notabene.ru/wi/article_9083.html

11. O. G. Kantorovich Rossiya: problemy vyrabotki natsional'noi strategii politicheskogo upravleniya sovremennymi mezhdunarodnymi konfliktami // Politika i Obshchestvo. - 2011. - 8. - C. 48 - 59. 